\title{
A comparison of North American and European railway systems - a critique and riposte
}

\author{
Phil Mortimer • Dewan Md Zahurul Islam
}

Received: 27 March 2014 / Accepted: 19 September 2014 / Published online: 9 October 2014

(C) The Author(s) 2014. This article is published with open access at SpringerLink.com

\begin{abstract}
Purpose The objective of current paper is to offer constructive criticism and expose some serious shortcomings in the paper published Clausen and Voll (Transp Res Rev 5:129-133, 2013) in the ETRR.

Method A literature review method is applied for the current research paper. A technical and scientific discussion, including organizational and policy issues in relation to rail freight transport systems in Europe and U.S., is performed.

Result Clausen and Voll [4] ostensibly set out to draw comparisons between North American and European railway systems. It claims to be focused on the management and operation of carload freight and how this is organized, planned and moved but does not develop this in adequate detail. The paper fails to address many generic contextual differences and influences that govern the management and operation of carload freight in both domains. It does not present a balanced or complete set of arguments as to why one scenario is to be preferred to the other.

The analysis in the paper is largely generic, limited and yet arrives at robust and trenchant conclusions preferring the North American production model without any real substantiation or justification for this position being presented. The European position is inadequately described in terms of governance, ownership and operational models and is criticised for its constraints and limitations without any real explanation as to how these could be overcome. The relatively slow evolution of the response of the US railroads to the legislation that endowed them with greater commercial and operational freedoms is not adequately covered. The position in Europe in
\end{abstract}

P. Mortimer $\cdot$ D. M. Z. Islam $(\bowtie)$

NewRail Newcastle Centre for Railway Research, Newcastle

University, Newcastle upon Tyne NE1 7RU, UK

e-mail: dewan.islam@newcastle.ac.uk relation to a rapid sequence of interventions and directives is also not adequately reviewed.

The paper does not demonstrate the impact of recent technologies in terms of intermodal activities despite these being significant components of rail freight volume and revenue in both domains. The paper also has very limited details on the commercial and competitive realities faced by railways in both domains including rail-on-rail, waterway and road based competition and how this is managed by the train operators. The paper makes superficial reference to the "Blocking Problem" but fail to develop what this implies and how the rail freight operators develop strategies to mitigate this.

Keywords Constructive criticism $\cdot$ Rail freight . Consolidation · Europe $\cdot$ U.S. wagonload · Carload · Learning lessons from each other

\section{Purpose}

This paper has been developed to expose some serious shortcomings in the content and conclusions of the paper written by Clausen and Voll [4]. Their paper discusses much of the economic issues surrounding European wagonload freight services and attempts to relate this back to infrastructural and institutional differences between the US and Canada and the generalised European model. Wagonload in the European context applies to the movement of cargo in individual wagons or wagon groups between a loading point and delivery point with these single units or groups marshalled into train length formations for the longer transit. The wagon types for this are multitudinous and includes covered wagons (sometimes designated as vans) capable of carrying a wide variety of merchandise traffic. They can also be used for the movement of palletised or unitised commodities such as lumber, bagged minerals (cement). In the European context these 
types of vehicles can be either twin axle or four axle designs. Wagonload can also include hopper wagons for the movement of fuels, minerals, ores, timber again of varying size, weight and volumetric capability. Tanker wagons are also used in wagonload traffic to service the oil and chemical sectors. The intimation in the paper is that the North American model is inherently a more efficient and effective option without analysing much of the context that underpins the differences. It omits recent major railroad consolidations, the rapid rise of inter-modal freight, the rising importance of the regional and short line operators and growth within the US railroad sector for block trains and also a strong residual market for carload (wagonload) traffic commodities some of which move in carload blocks. The term carload in the North American context applies to those movements undertaken in separate rail vehicles which can include box cars of varying dimensions which are used primarily for higher value merchandise traffic and can be moved in single units or as blocks of vehicles to be assembled into train formations for long haul movements. Box cars can also be used to move products such as grain and lumber. Other carload traffic can include hopper wagons for minerals, agricultural products, solid fuel (Iess common now), ores and similar products, tank cars for liquids, powders, granules, pellets and gases. Again these types of rail vehicle can be moved as single units or as parts of a group of vehicles). It also appears to downplay the routing and scheduling options that exist between the Class 1 and regional railroads with short line operations to facilitate carload or carload block movements. [2], p. 1) defines that U.S. Class I Railroads are line haul freight railroads with 2010 operating revenue of $\$ 398.7$ million or more. The AAR (American Association of Railroads, effectively an industry representative body) $(2013$, p. 1) reports that there are over 560 freight railroads of which only seven are "Class I" railroads that accounts for $69 \%$ of freight rail mileage typically operating in many different states. The AAR [1] report also suggests that the non-Class I railroads, also known as short line and regional railroads, range in size from tiny operations with handling of a few carloads per month to multi-state operators not far from Class I size.

We think that the abstract of the paper by Clausen and Voll [4] is weak and inconsistent. Some results of the paper are discussed in 'method'. There are contradictions between 'results' and 'conclusions'. For example, without any indication in the 'Result', it concludes that Europe can learn a lot from North American railway planning models' without any logical linkage or supporting evidence.

We are in the opinion that the title of the original paper is to some extent misleading due to the fact that it is mainly focused on wagonload traffic (see for example, purpose, section 2 etc.) and not 'railway systems' in the broadest sense that include much more than just 'wagonload' freight but all types of cargo including trainload and inter-modal traffic as well as other components of railway systems such as signalling/control, infrastructure issues etc. although there is some peripheral mention of infrastructure and institutional issues.

The assertion that the share of fixed costs in total transport costs is higher in Europe when compared to the US \& Canada is self-evident given the shorter sector distances and higher modal competition from road freight in Europe at a national and international level. This appears to discount the huge and long established contextual differences between the systems being compared in terms of geography, vertical ownership of long wholly owned routes (infrastructure), limited crossborder issues and long established high levels of technical and commercial inter-operability in the North America. There are also a large number of small yards, terminals, spurs and sidings to deliver and collect freight cars for carload and carload block operations. These are still being actively developed by the railroads in the US using a mixture of private and public funding

There is some confusion between the North American model which allegedly focuses primarily on finding short transit times and routing for each freight carload and the European model which the Clausen and Voll [4] intimate focuses on consolidation and high train utilization. For North American carload and carload blocks these are manipulated as required in classification yards in transit although the number and gross capacity of these yards has declined dramatically in response to block trains becoming much more the preferred model. There has also been a significant amount of modal transfer into inter-modal (domestic and international) with highly productive trains operating between major terminals and also the loss of merchandise traffic to road transport where transit times and service/product quality parameters are not adequately provided by the rail operators. Carload remains a significant component of North American rail freight.

In mainland Europe wagonload and wagon block traffic remains a significant although threatened element of the railway's portfolio of service options. These include a mix of publicly (or incumbent) and privately (new entrant) provided services covering a wide array of origins, frequencies, commodities and equipment. Given the wholly different geographical and operational context (much shorter transits, robust road based competition and competition for train paths with passenger trains) the model adopted in Europe sensibly reflects the need to consolidate wagons and wagon groups and to secure intensive equipment utilization. Clausen and Voll [4] suggest this reflects very centralised railway traffic pattern in Europe. This is challenged as the individual national patterns of operations vary widely. The evolving position of ownership and consolidation within the North American railroad scene is also following this trend as the Class 1 railroads seek to maximise their revenues by retaining traffic on their systems for as great a part of the transit rather than interchange with other lines. 
The authors are opaque as to what Europe can learn from North American rail road planning models. There is no mention of what North America may learn from Europe in the Clausen and Voll [4] paper. We are in the opinion that the North American railroads can learn from European railways as well for example, many are operating successfully under so many restrictions. Similar views on learning lesson is expressed by Boyer [3] who states that 'One way of preventing the capture of profits by varying trackage charges is to mandate uniform charges per mile of track regardless of track condition, timing, location, or traffic level. This is currently how pricing is done for highways and is the basis of the current European system of separating track fees from transportation charges.' It is also unclear from Clausen and Voll [4] as what the potential for decentralised traffic in European railway freight traffic might be and what this might achieve. There are more fundamental issues the freight rail operators need to address before slavishly adopting models which may not be appropriate. Section-wise and more specific comments on Clausen and Voll [4] paper are noted below.

\section{Introduction}

Rail freight has despite the major recent economic recession grown, as has rail passenger traffic, in recent years in response to a mix of technical, operational, ownership and governance changes. This has been true of European systems leading to expressions of concern for capacity and the development of new infrastructure. In North America which has a much more limited passenger traffic base rail freight has grown with particular strength in inter-modal and single commodity block trains. An important aspect of the successful of U. S. railroad is the deregulatory measures: the Railroad Revitalization and Regulatory Reform Act known as or 4R Act of 1976; the famous Staggers Rail Act (SRA) of 1980; and the last but not least the Interstate Commerce Commission (ICC) Termination Act of 1995 (ICCTA) that allowed the operators to work in a better competitive environment. This has resulted in not just a fewer but stronger Class 1 railroad operators $[3,14,11]$. The deregulation has benefited the customers as well. For example, [1], p. 3) claims that average rail freight rates (measured by inflation-adjusted revenue per ton-mile) were $44 \%$ t lower in 2012 than in 1981. North American rail freight still includes a high proportion of carload or carload groups and this reflects the remaining high availability of sidings, spurs and industrial branches together with the pro-active regional and small line railroads that actively support and service this type of traffic. The regional and short line model may be an option to be developed much further in Europe as a means of capturing traffic back to rail.

In Europe the withdrawal of services and the removal of infrastructure that previously supported wagonload freight has been an ongoing feature as rail has retreated or abandoned traffic primarily to road services. In addition rail in Europe has been less-well focused in terms of developing new sidings and industrial sites with a rail connection as an integral part of the railway's product and service portfolio compared to North America as commercial and industrial criteria and siting requirements have evolved. Some national railway operators in Europe (e.g. SNCF) have again been considering the reduction or abolition of wagonload traffic activities as a cost saving measure. Reducing the cost of operation, enhancing productivity and generating net new incremental revenue to achieve profitability do not appear to have been synchronised initiatives to maintain wagonload activities as part of a portfolio of rail freight services.

Rail in Europe is faced with universally available, aggressive and highly competent road freight services for domestic and international traffic over relatively short distance sectors across the entire commodity spectrum and it dominates the inter-urban freight market. As a consequence rail has lost share in the higher value, time sensitive flows (which are governed by imperatives the rail sector has had difficulty accommodating) that have emerged and as a consequence tended to focus on the less demanding block train model for inter-modal and bulk commodity flows. Clausen and Voll [4]) appear to have overlooked the complex mass of technical, operational, managerial and governance issues that have led to the present position and appear to be favouring a position where benefits will only flow from the adoption of North American systems.

Rail freight in North America is also faced with aggressive and near universally available road transport for general and specialist cargo applications which has effectively displaced rail from short and medium sector transit lengths on grounds of cost, service levels, responsiveness and availability. The overall position of road freight is being questioned by the current administration in relation to the levels of emissions and congestion it generates as well as the levels of infrastructure attrition and wear attributable to heavy vehicle activity.

\section{Railway planning problems}

The need to be able to move single wagonloads or small wagonload groups (not necessarily for the same shipper or a common commodity but they could be) implies the use of train aggregation to a cost effective formation to justify the direct operational costs (train path, crew, traction, fuel, maintenance) and some form of contribution to overheads. These operations are undertaken at marshalling yards to concentrate the train and for the reciprocal dispersal of wagons at the identified receiving yard prior to final delivery. The model is well established and similar model or concept is applied in other transport sector as well, for example, maritime shipping 
and gives flexibility to train operators in terms of building, mixing and breaking down trains. The decision making criteria in terms of pricing, routing, manipulation in transit can vary widely and be influenced by shipper requirements (urgent transit, lower order priority) and also the railroads desire to maximise its revenue if wagons/railcars are, in the case of the U. .S/Canada, needed to be exchanged with other lines. Issues such as running rights and traffic exchange are well established aspects which the authors are opaque on. A recent European Commission funded (under FP6) project [13, 12], which has been subsequently converted into a wholly commercial operation after the funding was ceased in August 2012, was based around two primary hubs for traffic aggregation and dispersal with a long haul sector over international routes using a mix of incumbent and privately owned traction and wagons and the involvement of many terminal and shunting service providers to aggregate and disperse the wagons and wagon groups. The Retrack Trains, operated by new entrant SME operator, were run to a schedule rather than building train length and weight to justify the long haul moves. Some of the Retrack trains were of very limited length as the service was developed but operated to sustain shipper confidence and also for traction and wagon balancing.

The planning problems, as elucidated by Clausen and Voll[4]), are essentially generic railway problems and apply in various forms in Europe and North America and present no immediate innovative insight. Railroads can chose (or not) to link the tactical perspective and the live operational phase which can and is subject to a mix of internal and external influences (e.g. seasonal traffic commodity demands, weather, interchange options). The use of system wide "war rooms" allowing the whole railway to be seen as an entity has been used by the larger Class 1 railroads in North America and European railways are moving to a similar scenario with reduced numbers of control centres. The higher density of traffic plus the volatile demands of the passenger component (domestic and international) imply the requirement for a different set of response mechanisms and balancing of passenger and freight priorities.

Clausen and Voll [4] claims that 'Section 2 provides information about planning processes in wagonload traffic in general.' There is no detailed or developed discussion on US wagonload planning policy, issues or the generic context. The paper poorly defines the 'Blocking Problem' which is the apparent central theme of the paper.

The tactical planning problem which Clausen and Voll [4] develop in their paper reflects a position primarily aimed at cost reduction rather than seeking revenue/profit maximization and has become detached from the prevailing operational and commercial pressures set by shippers. The routing of wagons / freight cars either individually or in blocks is subject to a mass of technical, operational and commercial imperatives so a generalised model (Blocking Problem) aimed primarily to reduce costs could readily lose touch with the reality of sustaining a routinely commercially competitive portfolio of service offers. The impact of inter-modal traffic further complicates this position with a range of product and service offers available in North America including trailers on flat cars (TOFC), twin stack domestic and twin stack international containers. These very high productivity options are not yet available in Europe although European inter-modal traffic operation is so far efficient and effective within the constraints of the infrastructure.

\section{Survey on railway models}

The author's review of the Blocking Problem was focused on certain key aspects required for their comparison of European and North American planning systems, methods \& problems in railway freight traffic. The section in the Clausen and Voll [4] paper "Survey on railway models" could usefully have included a diagram or graph to show the network and nodes with arcs, yards, stations and the other components but these are again not described in detail.

The use of the directed graph option as a device to model a rail road network is not contested but as with all modelling safeguards and vigilance is required to maintain integrity. The constraints identified by Clausen and Voll [4] are generalised. The "split table" allows variable routing by wagons/carloads. This overlooks the imperatives that govern the shipment which may favour a particular routing option to ensure on time arrival even at a revenue penalty such as an earlier or less favourable handover to another system or systems from the originating railroad. Alternatively if there is a lower order of priority for wagons/carloads to be held awaiting available traction and train services then alternative routes and schedules may be invoked. These are the commercial and competitive realities under which the train operators engage and offer their train services with differing degrees of priority. Intermodal traffic operation adds a wholly different dimension to all of this.

North America railroads retain, as intimated earlier, many routing options and infrastructure for what is effectively largely domestic traffic. European railway undertakings have to contend with a multiplicity of international borders (facing bureaucratic and time consuming cross-border clearance issues that are absent for trucking companies) although these are now of lesser significance than in the past. The routing preferences may vary within a national domain and this represents a measure of resilience and connectivity that yields benefits in the event of disruption. The European 2011 White Paper on Transport outlined that infrastructure has to be planned in a way that maximises the positive impact on economic growth and minimises the negative impact on the environment [9]. The recent designations of freight and passenger corridors The Core Network Corridors - that are aimed provide the 
essential infrastructure for carrying freight and passenger [7]. Now the European railways tend to emphasise the high capacity main lines as the preferred axes where investment has been channelled to accommodate high volumes of traffic. In some respects this is not dissimilar to the focus on the main lines within the major Class 1 railroads in the US and Canada as the primary conduits for traffic much of which is routinely moving between known origin and destination points.

The proportion of traffic which is effectively either new or established seeking an optimal (time of departure/time of arrival/cost/security/reliability) routing options as a proportion of total traffic within any railroad domain is governed by a mass of internal railway and external shipper requirements. The proportion of repetitive business using established or preferred routing can vary but high levels of contracted repeat business comprises a high proportion of carload rail traffic activity. Shippers can elect to nuance their movement patterns as part of their particular supply chain activities and operational and commercial priorities.

For a new market entrant (not an incumbent) in Europe the ability to offer a range of point to point options or bespoke services has been demonstrated by the RETRACK [13] project. Rail has, and this has accounted for some loss of markets to competing modes, not generally been able to respond as adequately to shipper's enquiries for very short term and spot type movements to the same extent as road freight because of the inability to indicate service availability options, schedules, routes operated, space and weight availability leading to traffic attrition. The development of initiatives such as the recently launched Freight Arranger (details on http://freightarranger. co.uk/) system in the UK is an example of how these issues can be addressed and resolved within one system. Governance issues including open access and the relatively lower priority afforded to freight in Europe go some way towards explaining this. The North American Class 1 railroads by comparison are vertically integrated and operate along wholly commercial lines against other major and regional rail operators and strong road and river based freight competitors.

The formation, classification, re-classification in transit and ultimate delivery of rail cars to receiver's sidings and depots is a fundamental part of railway operating practice but one which has declined in the face of road based competition for short and medium haul sectors. The emergence of inter-modal options has deleted the need for some of this activity with the inter-modal units being moved to/from the terminals and railhead by truck. The need for intermediate re-classification or marshalling is reduced as a consequence but rail has participated in flows from which it might otherwise have been excluded. Certainly containers/TOFC can be and are moved between trains and this implies a cost but the railroads in their rate making build this component into their commercial positioning. The use of pre-formed wagon/carload blocks to minimise terminal dwell time is also an option. The constraints identified in Table 1 (in [4], p. 131) are effectively the business norms within which the railroads operate.

\section{Comparison of European and North American railways}

This section effectively sets out a sketch of the primary differences between the North American and European rail freight positions. The U. S. undertook reforms (in particular SRA of 1980) effectively to stop most of the railroads going under financially in the 1980s. It took a long time for the full freedoms (freedom to negotiate secret rates with shippers, labour reform, the option to reject non-profitable traffic etc.) to be recognised and turned to positive commercial effect [3, $14,11]$. In contrast, the European Railways are yet to implement such reforms, although the European liberalization process has been effectively an accounting means to get a grip on the levels of expenditure being made by the national incumbents on infrastructure and operations. The degree of application and reform including open access to new entrants has also been diverse within the EU. Some consolidation and acquisitions have been made within Europe and there is continuing debate about the ownership model which is competitive and transparent.

North American railroads are primarily focused on freight with minimal interaction with passenger traffic other than around major cities. In Europe passenger traffic activity has grown and is a constraint on making freight path availability particularly given the length, weight and low power to weight ratio of existing freight train technologies (e.g. with on average axle load of 22.5 to 25 tonnes as opposed to 32-35 tonnes in the U. S.). Freight is moved during the day in many European countries despite the original author's apparent belief that this is not feasible. Much depends on the scheduling of the full array of passenger and freight services requested to and approved by the infrastructure manager and the ability to manipulate these if not required or they are compromised by delay. We agree with the idea that the wide variability of train length maxima within Europe is a constraint but we disagree with the notion that North American trains are totally unrestricted as issues such as train weight, braking, gradients, power requirements and the ability to enter/exit terminals or yards are germane. The North American position is not as wide open as the authors appear to indicate. Train lengths in North America have traditionally been much longer than in Europe reflecting the geographical context and the nature of the operations (largely unscheduled with freight awaiting a justification point for an operation to be undertaken) although there has been a recent move towards many more scheduled operations. Europe by comparison had perforce to work within a more disciplined scheduled position imposed by meeting passenger train requirements first. Again we refer to the RETRACK [13] train operation that was routinely able to 
secure train paths through some of the most active and intensively used rail lines in Europe on an ad-hoc basis and has continued to do so since the project moved into full scale commercial operations following initial support from the EC. Clausen and Voll [4] do not develop the position on the extent of the railway reforms and various follow up measures designed to drive the whole strategic move into a more liberalized and competitive position including rail on rail and rail on road competition. Some countries (e.g. UK) have adopted the full separation model and driven the pace of reform simultaneously with privatization and the advocacy of open access. Other incumbents have been slower to adopt the reforms (e.g. SNFC) and are being pursued by the EC for a failure to comply.

Twin stack has been a relatively new but eminently successful development $(30+$ years in the making) in North America for domestic and international container traffic where the generosity of the loading gauge has allowed this option to be exploited. Maximum train lengths in Europe reflect the constraints of the existing technology; operations and commercial models the rail operators have perforce to work within. The increasing use of block trains and wagonload/carload blocks with a minimum requirement for intermediate marshalling or re-classification offers a means of enhancing competitiveness within these constraints. The economic impact that resulted in the withdrawal of rail facilities in much of Western Europe to service industrial and commercial sites is to be regretted. Rail will have to re-position itself to this either by re-investment and the re-commissioning (e.g. being done in the UK) of such links or advocate the inclusion of rail lines in any new major logistics developments as an integral planning requirement if it is to come back into contention with wagon/ carload based traffic and commodities. Inter-modal as an option has major advantages but is not wholly appropriate for all traffic applications.

To be competitive and cost competitive implies challenging the existing operational, technical and commercial models, driving asset productivity up by factor levels and the reciprocal of taking costs out to compete with alternatives. More but possibly smaller point to point traffic flows with no need for intermediate manipulation or classification based on much reduced response times, rapid path, crew and resource allocation would represent a major advance and bring rail into contention for more wagon/carload or wagon group traffic. Recent deliberations within the UK based Freight Transport Association (FTA) were aimed at the possibility of using wholly different train formation sizes and concepts with the possibility of smaller but faster trains able to operate at passenger train speeds [10]. The ability to access and depart more readily into terminals, sidings and logistics parks to expand rail's market "reach" compared with orthodox long formations also underlines the potential of this approach. Rail will need to maximise the energy efficiency and speed endowments it has to regain competitiveness. The differential in speeds between passenger and freight trains is a limitation where these flows conflict particularly at peak times. Driving up freight train speed using orthodox technology implies the use of multiple or more powerful locomotives at additional cost (ultimately to be reflected into pricing). The length of freight trains also has implications for train sequencing and how to respond to disruptions in train operations. Neither of these points was developed or discussed by Clausen and Voll [4].

\section{Conclusions for planning processes}

Clausen and Voll [4] conclude that the North American railroads are able to move wagons through their networks relatively much cheaper than in Europe. They fail to develop or address the major contextual differences including ownership, governance, absence of intensive passenger traffic and the retention of many rail linked sidings, and spurs that can support a many-to-many set of routing options. Equally the absence of restricting international borders and longer sector lengths is passed over. Rail in North America is not particularly competitive or effective at sector lengths of less than 500 miles and has abandoned or been driven out of sector length flows of this distance or less. Movement costs are claimed to be a lower proportion of total costs in North America. The focus on individual car movement costs disaggregates the decision making process down but neglects the routine commercial position where wagons/freight cars are moved in groups or blocks from a common point to a common destination where this degree of detail, whilst useful, for management and commercial purposes can be irrelevant or unnecessary. The focus on individual car costs as the primary routing decision making item potentially drives routing solutions to constrained paths or routes which can then trigger issues of capacity and cargo priority. The reality of shipper revisions of traffic in transit, changes in routing preference, scheduling, equipment types and a host of other practical issues are not discussed yet they have a major bearing on the reality of moving rail freight. . The deletion of the need to move wagons/freight cars through classification yards is an increasingly common trend with preformed blocks of wagons grouped into formations but is not discussed or elaborated upon.

The authors' explanation of the apparent higher costs in Europe is not clearly developed or explained. Wagonloads and wagon groups are aggregated within individual railway domains (national traffic remains a high proportion of total traffic activity so control is retained by the train operators/ service providers on a basis similar to that as practices in North America). A many-to -many service network was offered by rail operators in the not too distant past but failed to 
respond and develop to evolving location and service criteria better provided by road freight. Such a network operation would be prohibitively expensive to own, operate and maintain for low and intermittent traffic volumes using existing technology, operational and commercial models and also be unattractive compared with road based alternatives that can and do offer services that rail of itself cannot provide. Intermodal traffic operation options go some way to offset this using terminal networks for domestic national traffic flows (including deep sea containers and also freight compatible with unitised modules) and also for international traffic within Europe. The assertion that fixed costs account for up to $50 \%$ of the total costs of train operations is not substantiated nor is the contention that costs of train operation are not linked significantly to the degree of capacity (line? wagon assets?). As a result of the Railway Reforms Packages, European train operators have had to acknowledge and absorb the cost of train paths and compete for these with other operators and other types of train services and reflect them in their cost structure and pricing.

Within a closed system in North America how train path costs are identified and allocated to a specific train or wagon movement is not clear cut and is complicated by issues for example such as time available for use but not utilized. How this dead time is attributed or allocated as a cost function is also not addressed. At least one of the Class 1 railroads had until recently no clear idea as to where it was spending capital on infrastructure, how much it was spending and what the return on the investment was likely to be and how this was derived and validated. The North American position is not necessarily more developed than that in Europe (see for example, [3]) as the authors claim. Both systems have been reformed from without which speaks volumes as to the railways ability (or inability) to successfully identify and address key strategic governance and commercial issues.

It is far from clear in the Clausen and Voll [4] paper that Europe can learn a lot from North American practice. The European railways were virtually all state owned and financed by governments/ministries. Financial and accounting practice varied widely together with issues such as deficit financing. The Railway Reform Packages (in particular the First Railway Package) were initially aimed at splitting infrastructure and operational accounting $[6,5]$ but has blossomed into a much wider package of reforms (for example in the Fourth Railway Packages) aimed at driving the European rail sector into a more competitive posture [8]. This is still an evolving process. Response to the Staggers Act took years to be absorbed and developed successfully. Clausen and Voll [4] do not recognise this in their paper. The distance context, acute short haul road based competition, legacy issues as how industrial and commercial patterns have evolved, interaction with passenger services and a mass of varied national technical and operating criteria are not new in Europe.
Wagonload freight on a mass point to point operation with low and intermittent traffic volumes has been virtually wiped out or is planned to be seriously downgraded in several European domains. Existing train technologies, operating methods and commercial practice are perceived as being increasingly inappropriate for shipper's requirements which have been fully fulfilled by a dynamic road freight sector which has set the bar in terms of service, cost, availability, reliability and responsiveness. The whole rail freight product and service offer needs to be wholly and rigorously transformed if it is to retain a measure of competitiveness and attractiveness to shippers who do after all have modal options to work with.

Clausen and Voll [4] advocate the adoption of a more flexible and more efficient European railway system to reflect the North American model. This is too simplistic. This implies some strategic changes in terms of asset management, responsiveness in terms of service availability, space and weight availability, dynamic scheduling and line capacity management/path allocation as well as driving productivity higher on a much reduced cost base. These issues are being addressed and it is simplistic to suggest they are not. The RETRACK [13] freight train operation put down markers as to what could be achieved operating a fully privatized international wagonload/wagon group service between two primary concentration points with traffic assembled and dispatched between these. The movement of wagons/wagon groups to and from these was overseen by local shunting service providers but the cost element of this was reflected in the pricing. The option of "satellite" movements on/off the main line of route (Cologne-Budapest) was also developed and demonstrated the flexibility of the concept. The notion of following a "pure strategy" approach which entails a unique successor node for traffic with common or near common destinations is not tenable. The railways need to be as flexible and responsive as possible to the shipper's requirements and not be setting a rigid supply side position.

Clausen and Voll [4] appear to be in thrall of the North American model and suggest the adoption of concepts, techniques, systems and methods to support rail freight activity in Europe. This is challenged at a strategic level and in detail. The wholly different governance, technical, operational and competitive context precludes much of this.

\section{Summary}

Clausen and Voll [4] emphasise the complexity and issues arising within the European position with passenger and freight trains operating simultaneously. We argue that this works well in many European railway domains and thus should not be disparaged. They conclude that there needs to 
be a balanced trade-off between transport costs and classification (marshalling). We think that for a growing proportion of European rail freight classification is irrelevant as point to point operations have developed to maximize asset productivity and commercial competitiveness using current technology and operating models. The downside of the concentration on block trains and wagon groups is that there is a risk that rail is not able to compete for small and intermittent traffic flows using a universal train type product and service model. Rail needs to think about how it may address this much more complex and dynamic sector and develop attractive and competitive options. The replacement of wagonload by domestic inter-modal services may go some way to addressing the loss of competitiveness using orthodox train technologies and operations but there are real limitations on this in terms of the compatibility of loading gauges to allow large inter-modal units and trailers to circulate widely on rail.

Clausen and Voll [4] allude to the need to abandon "pure strategy" to make planning processes more flexible. We argue that many European rail freight operators already do this on a routine basis with a move from long term through to real time train planning/cargo allocation and movement plans all being very flexible to reflect commercial and operational positions. The RETRACK [13] freight train operation model gives some considerable insight and offers a good starting point to demonstrate exactly what the authors are suggesting to abandon ([4], p. 132) was successfully applied in practice recently. We agree with the authors that further scientific and robust research is needed to explore the issues further.

Open Access This article is distributed under the terms of the Creative Commons Attribution License which permits any use, distribution, and reproduction in any medium, provided the original author(s) and the source are credited.

\section{References}

1. Association of American Railroads (2013) Overview of America's Freight Railroad, April, p.1

2. Association of American Railroads (2012) Class I Railroad Statistics, AAR - Policy and Economics Department, 10 May, p. 1

3. Boyer, K. D. (2014) Why is the Rail Share of US Freight Traffic So Low? Journal of Transport Economics and Policy, Vol. 48, Part 2, May 2014, pp. 333-344

4. Clausen U, Voll R (2013) A comparison of North American and European railway systems - Why Europe needs particular optimization models for railway freight traffic, European. Transp Res Rev 5: $129-133$

5. CER (2008) European Railway Legislation Handbook, Eurailpress

6. CER (2006) Competition in Europe's rail freight market. DVV Media Group GmbH Eurail Press, Hamburg

7. European Commission (2013a) The Core Network Corridors- TransEuropean Transport Network (TEN-T), Directorate General for Mobility and Transport, Brussels, September, pp. 2-44

8. European Commission (2013b) Press Release on European Railways at a junction: the Commission adopts proposals for a Fourth Railway Package, Brussels, http://europa.eu/rapid/press-release_IP-13-65_en. $\mathrm{htm}$, last accessed on 11.02.2013

9. European Commission (2011) White Paper: Roadmap to a Single European Transport Area - Towards a competitive and resource efficient transport system, COM (2011) 144 final, Brussels, 28 March

10. Freight Transport Association (2014) The Agenda for More Freight by Rail, Freight Transport Association, UK, May, http://www.fta.co. uk/export/sites/fta/_galleries/downloads/rail_freight/14094_agenda_ for_more_guide.pdf

11. Posner III, H. (2008) Rail Freight in the USA: Lessons for Continental Europe. CER Essay SERIES - The Voice of European Railways, CER, January

12. RETRACK (2014) The RETRACK Project - REorganization of Transport Networks by advanced Rail freight Concepts, Home page, project website http://www.retrack.eu/, last retrieved 27/03/2014

13. RETRACK (2012). The RETRACK Project - REorganization of Transport Networks by advanced Rail freight Concepts, Final Report, November, TNO, Delft, NL, project website http://www. retrack.eu/, last retrieved 22/03/2013

14. Spychalski JC, Swan PF (2004) U. S. rail freight performance under downsized regulation. Util Policy 12:165-179 